\title{
Evaluation of Indigenous and High Yielding Rice Varieties for Growing in Tidal Floodplain Ecosystem of Southern Bangladesh
}

\author{
Mohammad Jafar Ullah ${ }^{1,2}$, M. Aminul Islam ${ }^{1}$, M. Harun-or-Rashid ${ }^{3}$, M. Moksedur Rahman ${ }^{1}$, \\ M. A. Siddique ${ }^{1}$, M. Ali Akbar ${ }^{1}$, Mohammad Abdur Razzaque ${ }^{4}$, M. Faruque H. Mollah ${ }^{1}$, \\ Abdul Hamid, ${ }^{1, *}$ \\ ${ }^{1}$ Agrarian Research Foundation, Dhaka, Bangladesh \\ ${ }^{2}$ Department of Agronomy, Sher-e-Bangla Agricultural University, Dhaka, Bangladesh \\ ${ }^{3}$ Department of Agronomy, Patuakhali Science \& Technology University, Dumki, Patuakhali, Bangladesh \\ ${ }^{4}$ Krishi Gobeshona Foundation, BARC Complex, Farmgate, Dhaka, Bangladesh
}

\begin{abstract}
Email address:
jafarullahsau@gmail.com (M. J. Ullah),makrahman@yahoo.com (M. M. Rahman),msiddique@gmail.com (M. A. Siddique), kbdaliakbar@yahoo.com (M. A. Akbar),nilumar@gmail.com (M. A. Razzaque), faruque_agr@yahoo.com (M. F. H. Mollah), hamid50.arf@gmail.com (A. Hamid)

${ }^{*}$ Corresponding author
\end{abstract}

\section{To cite this article:}

Mohammad Jafar Ullah, M. Aminul Islam, M. Harun-or-Rashid, M. Moksedur Rahman, M. A. Siddique, M. Ali Akbar, Mohammad Abdur Razzaque, M. Faruque H. Mollah, Abdul Hamid. Evaluation of Indigenous and High Yielding Rice Varieties for Growing in Tidal Floodplain Ecosystem of Southern Bangladesh. Agriculture, Forestry and Fisheries. Vol. 5, No. 6, 2016, pp. 237-242. doi: 10.11648/j.aff.20160506.14

Received: September 1, 2016; Accepted: September 10, 2016; Published: October 27, 2016

\begin{abstract}
Growth and yield of three indigenous varieties (Lalmota, Moulata and Sadamota) of aman rice was compared with that of two high yielding varieties (BRRI dhan 41 and BRRI dhan 44) in tidal floodplain ecosystem for two growing seasons. $45 \mathrm{~d}$ old seedlings transplanted in seedbed experienced repeated cycles of tidal submergence. Depth and duration of tidal flood differed between two growing seasons. Compared with high yielding varieties (HYVs), indigenous varieties developed longer seedlings and accumulated more dry mass prior to transplanting that helped survive repeated submergence. Planting density of indigenous varieties was about the half that of HYVs but developed more tillers per unit areas than HYVs. Seedlings of HYVs that survived had moderate tillering. HYVs ceased to develop tillers prior to flowering stage but the indigenous varieties continued growing tillers till maturity. In 2011-2012 season, HYVs produced higher yield than indigenous varieties but the trend reversed in the subsequent growing season. Number of panicles per unit area, number of spikelets per panicle, and 1000grain weight largely contributed to higher yield. In absence of submergence tolerant HYVs, growing of indigenous rice varieties in the south central coastal region of Bangladesh could be the farmers' better choice.
\end{abstract}

Keywords: Indigenous Rice Varieties, On-Farm Trials, Seedling Height, Tidal Floodplain, Growth Stages, Tiller Density, Grain Yield

\section{Introduction}

Croplands in tidal floodplain of south central coastal districts of Bangladesh (Jhalakati, Barisal, Patuakhali, Pirojpur and Barguna) are subject to intermittent or continual submergence due to tidal flooding for an extended period during the year. The upper segment of the estuaries of the rivers Bishkhali, Payera, Kocha and Baleswar are generally non-saline and thus crop production in this tidal floodplain is not constrained due to soil salinity [1]. But topography and hydrological conditions present problems in growing high yielding varieties (HYVs) of rice during rainy season. Transplanted aman rice faces challenge of submergence due to tidal flood water of varying depths and intensity. However, information on the depth of tidal flood, time, intensity, extent of flooding and their impact on rice production is generally 


\section{lacking.}

High yielding, short statured rice varieties do not fit in tidal floodplain during rainy season. Instead of HYVs, farmers usually grow low yielding, indigenous varieties which are mostly photo-sensitive, tall, and of long duration. Four indigenous varieties or landraces - Moulata, Lalmota, Sadamota, and Dudhkalom dominate in the tidal floodplain in Jhalakati and Pirojpur districts [2]. These varieties can survive usual tidal flood without substantial yield losses. Over years, farmers evolved some agronomic practices that apparently fit with these varieties. The varieties are of vigorous tillering habit and grown irregularly in widely apart hills. Farmers practice transplanting 10-30 seedlings per hills at wider spacing seldom applying any fertilizers. In order to cope with frequent tidal flooding of varying depths and across toposequence, farmers transplant aged seedlings (40-90 days old) [2]. Roy et al. [3] attempted to adapt high yielding rice varieties optimizing transplanting date. Recently Das et al. [4] reported planting method effect on aus rice in non-saline tidal floodplain. However, research comparing growth and yield performance of indigenous aman rice varieties and HYVs in the tidal floodplain ecosystem during aman season is inadequate or inconclusive. How the HYVs developed for tidal flood ecosystem perform compared with indigenous varieties has not been investigated adequately. Because of intermittent soil and crop flooding, irrigation is not required; but application of fertilizer remains a problem. Whether improved agronomic production practices could improve yield of these indigenous varieties requires to be investigated. It is against this backdrop, a series of field experiments, on-farm trials and adaptive trials were carried out in south central coastal district of Bangladesh to examine the adaptability of $\mathrm{HYV}$ aman rice in tidal floodplain.

This paper compares growth and yield performance of three indigenous rice varieties with two high yielding modern varieties grown in southern delta region.

\section{Materials and Methods}

\subsection{Experimental Sites}

Supervised on-farm trials were conducted in 16 farmers' plots dispersedly located in four villages in two upazila Rajapur and Jhalakati Sadar of Jhalakati district for the two successive aman seasons of 2011-2012 and 2012-2013. Each farmer dedicated a minimum of 0.134 ha of land for running the trial. Two villages - Sachilapur and South Kistakathi in Jhalakati Sadar upazila are about $1.0 \mathrm{~km}$ apart. Likewise, two villages Challish Kahnia and North Uttampur of Rajapur upazila are about $3.0 \mathrm{~km}$ away from each other. The two clusters of villages are about $9 \mathrm{~km}$ apart. Farmers in four villages however share almost similar environmental conditions including hydrology.

We had casual and qualitative observations on the extent and severity of tidal flood for the two growing seasons
(2011-2012 and 2012-2013). Depth and duration of flooding was more in the latter growing season.

\subsection{Experimental Materials}

Two modern varieties (BRRI dhan 41 and BRRI dhan 44) and three indigenous varieties (Lalmota, Moulata and Sadamota) were taken as experimental materials. Modern varieties are semi-dwarf, fertilizer responsive and high yielding and are extensively grown under irrigated condition elsewhere in the country. The selected local varieties, rather landraces, are photo-sensitive, of long duration, tall stature and relatively low yielding but adapted to local conditions and grown over ages. Based on the results of previous onfarm trials [5] conducted in preceding two years, two modern varieties (BRRI dhan 41 andBRRI dhan 44) and three indigenous varieties (Lalmota, Moulata and Sadamota) were used in this study. Selected farmers of four villages conducted the experiment growing five rice cultivars on their plots. The size of farmers' experimental plots, however, differed a great deal, but the minimum size was not less than 0.134 ha.

\subsection{Crop Culture and Management}

Medium lowland was selected for running the trials. The lands undergo tidal submergence during high tides July through October [4, 5]. Each farmer's plot was divided into five equal segments for accommodating varieties. Seedlings were grown on medium highland and transplanted 11-18 August in 2011 and 8-15 August in 2013. To avoid seedling damage due to tidal submergence, transplanting dates were selected corresponding to low tides when land remained either above flood level or the depth of tidal flood was shallower than the height of transplanted seedlings. Thus the seedling age at transplanting differed slightly between the growing seasons in order to synchronize with low tides. In view of the differences in growth patterns of indigenous and modern varieties, we maintained different transplanting configurations for two plant types. High yielding varieties were planted in rows $25 \mathrm{~cm}$ apart, and $15 \mathrm{~cm}$ between hills in the row. Indigenous varieties were planted at $40 \mathrm{~cm} \mathrm{x} 20 \mathrm{~cm}$ configuration following farmers' practice. Farmers usually do not transplant indigenous rice varieties in rows; transplanting seedlings in irregular zigzag fashion is generally practiced. Sampling from a large number of farmers' fields across locations immediately following harvest of aman (2011-12) we estimated that farmers maintain an average distance of $38-50 \mathrm{~cm}$ between hills. Tidal flooding usually causes substantial hill damage. We surveyed the hill density immediately after harvest and estimated average hill densities of the rice varieties planted.

Indigenous varieties were grown without fertilizer application. This was done to simulate the farmers' usual practice of growing rice. Modern varieties BRRI dhan 41 and BRRI dhan 44 received fertilizers at the rate recommended for irrigated rice elsewhere in the country. As no method was available for fertilizer application for growing rice in tidal 
floodplain ecosystem where water remains uncontrolled, we applied the whole amount of fertilizers including urea in the HYV plots after transplanting when the plots were not inundated by tidal floods. However, the prevailing hydrological conditions did not allow us to apply fertilizers on appropriate time. Both HYVs and indigenous varieties were grown with natural tidal water and no irrigation was required.

\subsection{Design of Experiment}

Trials conducted in four villages in two upazila during 2011-12 and 2012-13 involved 16 farmers. Each upazila represented by two villages with 8 selected farmers made up a cluster and a farmer considered a replication. Each farmer planted all 5 varieties dividing his parcel of land into five sub-plots. The trial was set up in a randomized block design. Since the two clusters of villages shared similar ecologies and environmental conditions, location or cluster of villages was not treated as an experimental variable. The trial thus comprised five varieties as treatments with 16 replications.

\subsection{Plant Sampling, Recording of Data}

Data were recorded on seedling characteristics (seedling height, seedling dry weight), hill density (number $\mathrm{m}^{-2}$ ), plant height, number of tillers $\mathrm{m}^{-2}$, dates to attainment of phenological events and yield attributes. Seedlings were sampled at random to measure seedling height prior to transplanting. For each variety three samples were taken from each location. 50 seedlings made up a sample. Seedlings were cleaned in water, segmented into root and shoot, oven dried at $70^{\circ} \mathrm{C}$ to a constant weight and dry weight taken.

Phasic changes of individual varieties were observed sampling plants and recording dates of panicle initiation, first flowering and 50\% flowering and physiological maturity recorded. The first flowering was marked when flowering of a plant in a plot appeared first and likewise when $50 \%$ of the hills in a plot flowered was considered as $50 \%$ flowering. At maturity, $10 \mathrm{~m}^{2}$ area of each variety was demarcated from the center of sub-plot and harvested cutting at the base. The panicles were threshed and grain yield recorded adjusting moisture content at $14 \%$. A random sample of 5 hills were harvested from each sub-plot leaving at least 7 rows of rice crop from either side of the sub-plot to record number of tillers per hill, height of longest tiller in the hill, number of panicles per hill, panicle length, number of spikelets per panicle, number of filled spikelets per panicle. Sub-samples of grains were taken to determine moisture content. Hill density (number $\mathrm{m}^{-2}$ ) was determined counting the base of harvested hills per unit area immediately after rice harvest. Weight of 1000-grain was recorded from the grain sub-samples taken from each treatment.

\subsection{Data Analysis}

Data were subjected to analysis of variance (ANOVA) and means compared employing Duncan's Multiple Range Test (DMRT) at $\mathrm{p}<0.05$ level of significance.

\section{Results and Discussion}

\subsection{Seedling Height}

Seedling height is an important character for establishing rice crop in tidal floodplain. In 2011-12 growing season, seedling height varied between $49.3 \mathrm{~cm}$ and $59.9 \mathrm{~cm}$ across varieties. Indigenous varieties (IVs) grew taller than HYVs. Two indigenous varieties Lalmota and Sadamota had accumulated significantly higher dry mass than other varieties while the HYVs had shorter seedlings and lower dry mass (Table 1) at transplanting.

Table 1. Varietal difference in rice seedling height and seedling dry mass at transplanting.

\begin{tabular}{lllll}
\hline \multirow{2}{*}{ Variety } & \multicolumn{2}{l}{ Seedling ht $(\mathbf{c m})$} & \multicolumn{2}{l}{ Seedling dry mass (g) } \\
\cline { 2 - 5 } & $\mathbf{2 0 1 1}$ & $\mathbf{2 0 1 2}$ & $\mathbf{2 0 1 1}$ & $\mathbf{2 0 1 2}$ \\
\hline BRRIdhan 41 & $50.1 \mathrm{~B}$ & $40.53 \mathrm{C}$ & $0.607 \mathrm{C}$ & $0.116 \mathrm{C}$ \\
BRRIdhan44 & $51.2 \mathrm{~B}$ & $42.36 \mathrm{C}$ & $0.731 \mathrm{~B}$ & $0.145 \mathrm{BC}$ \\
Moulata & $51.2 \mathrm{~B}$ & $51.91 \mathrm{~B}$ & $0.762 \mathrm{~B}$ & $0.168 \mathrm{BC}$ \\
Sadamota & $59.9 \mathrm{~A}$ & $63.26 \mathrm{~A}$ & $0.948 \mathrm{~A}$ & $0.341 \mathrm{~A}$ \\
Lalmota & $58.3 \mathrm{~A}$ & $56.01 \mathrm{~B}$ & $0.980 \mathrm{~A}$ & $0.200 \mathrm{~B}$ \\
CV $(\%)$ & $11.30 \%$ & $9.98 \%$ & $19.41 \%$ & $36.31 \%$ \\
\hline
\end{tabular}

The same letter(s) within each column are not significantly different at $\mathrm{P}<0.05$

Seedlings were relatively shorter in the subsequent growing season (2012-13), but the trend of varietal difference was similar. Seedlings of Sadamota were about $10 \mathrm{~cm}$ higher than that of BRRIdhan 44. In the 2012-13 growing season, varieties differed enormously in seedling height ranging between $40.5 \mathrm{~cm}$ and $63.3 \mathrm{~cm}$. Variety Sadamotahad the highest seedling length, nearly $20 \mathrm{~cm}$ higher than BRRIdhan 41. The tidal flooding depth at the early season of aman rice usually remains within $50 \mathrm{~cm} \mathrm{[5]} \mathrm{and} \mathrm{it} \mathrm{appears} \mathrm{that} \mathrm{the}$ seedlings of local varieties could tolerate flooding perhaps because of relatively greater seedling height. Tolerance to flooding may be attributed to rapid elongation and accumulation of greater amount of dry mass in seedlings of indigenous varieties [6]. In the present study seedling height of varieties was proportional to seedling dry mass suggesting that higher the dry mass, longer was the seedling and greater was the ability to cope with tidal depth.

\subsection{Phenology}

Since year to year variation in days to attaining phenological stages was the minimum hence we used two years' average in our analysis. Varieties differed widely in attaining panicle initiation stage. Days taken to attain PI stage varied between 82 to 116 days (Table 2). Significant variation was observed between HYVs and IVs in attainment of phenological stages. Both the HYVs attained PI stage much earlier than the local 
varieties. Lalmota and Sadamota took 34 days more to attain PI stage while Moulata attained PI stage 15 days later than HYVs. However, the difference narrowed down in flowering and physiological maturity stages (Table 2). Our observations are in agreement with Haque et al. [7] who reported wide genotypic variation in phenological events among 14 aus cultivars. Ahmed et al. [8] demonstrated significant differences in attaining phenological stages due not only to varieties but also to variable management practices.

Table 2. Varietal differences in attaining phenological stages of rice (Average of two years'data).

\begin{tabular}{llll}
\hline \multirow{2}{*}{ Variety } & \multicolumn{2}{l}{ Days taken to attain phenological stages } \\
\cline { 2 - 4 } & Panicle initiation & Flowering & Physiol. maturity \\
\hline BRRIdhan 41 & $82.0 \mathrm{C}$ & $100.7 \mathrm{C}$ & $147.4 \mathrm{~B}$ \\
BRRIdhan44 & $81.6 \mathrm{C}$ & $99.5 \mathrm{C}$ & $146.9 \mathrm{~B}$ \\
Moulata & $97.4 \mathrm{~B}$ & $113.6 \mathrm{~B}$ & $159.3 \mathrm{AB}$ \\
Sadamota & $115.7 \mathrm{~A}$ & $128.1 \mathrm{~A}$ & $171.5 \mathrm{~A}$ \\
Lalmota & $116 \mathrm{~A}$ & $129.4 \mathrm{~A}$ & $171.9 \mathrm{~A}$ \\
CV(\%) & 1.14 & 1.15 & 0.66 \\
\hline
\end{tabular}

The same letter(s) within each column are not significantly different at $\mathrm{P}<0.05$.

\subsection{Morphological Characters}

Number of tillers per hill or unit area is an important criterion contributing to grain yield in rice [10]. Both varieties and growing season exerted significant influence on the number of tillers per hill. In 2011-2012growing season, the number of tillers per hill was counted once at maturity but in the subsequent years we recorded tillering dynamics in three successive growing seasons. Compared with 2012-2013 growing season, the number of tillers per hill at maturity was generally high in all the varieties in the preceding growing season (2011-2012). However, the trend in difference across varieties was similar and hence we present 2012-2013 growing season data only. Figure 1 shows the variation among the varieties in the production of tillers per hill over three successive growth stages. HYVs of rice had identical number of tillers per hill at PI and flowering stages that declined at maturity stage. The number of tillers per hill was generally more in indigenous varieties in all the three growth stages. The number of tillers per hill in Sadamota and Lalmota was significantly higher while Moulata was intermediate in tiller production till flowering stage. HYVs had nearly constant number of tillers at PI and flowering stages but indigenous varieties continued increasing tillers per hill showing the highest at maturity stage. The number of tillers in HYVs generally declined past flowering stage; but no such trend was apparent in indigenous varieties. Interestingly, variety Moulata being intermediate in producing tillers until flowering stage, recorded the highest number of tillers per hill at maturity stage. The results suggest that indigenous varieties developed tillers even in ripening stage probably remobilizing stored photosynthates.

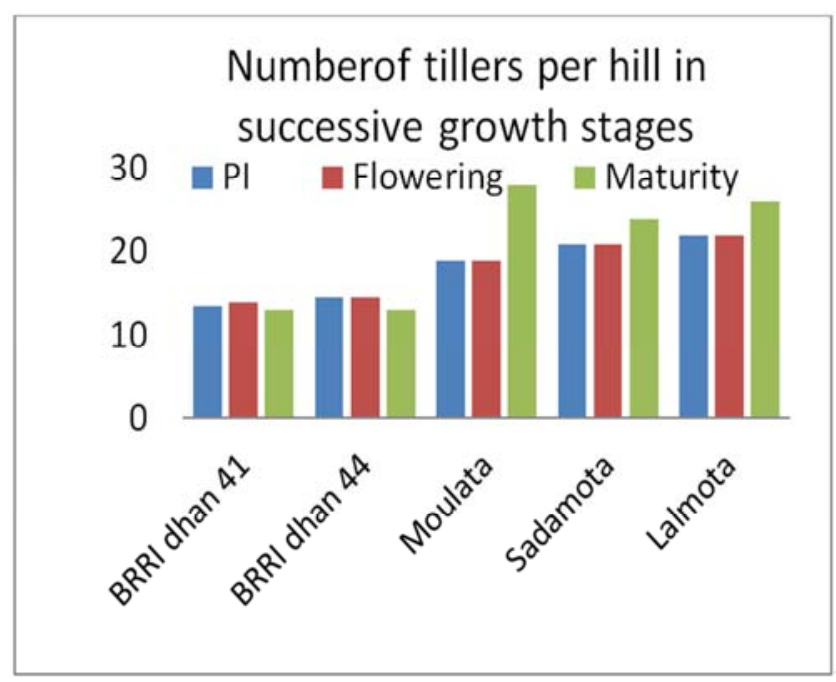

Figure 1. Differences in tiller development among five rice varieties.

Table 3 shows the varietal differences in tillers per $\mathrm{m}^{2}$ and plant height at maturity. Number of tillers varied from 205 to 240 per $\mathrm{m}^{2}$ across varieties. Indigenous varieties had almost double the number of tillers per hill compared with HYVs. Because of differences in planting configuration, hill density was higher in HYVs. But the larger number of tillers per hill of indigenous varieties more than compensated the hill density eventually producing greater number of tillers (231) per unit area compared to that of HYVs (211) at maturity. Two indigenous varieties Moulata and Lalmota had identical but significantly larger number of tillers per $\mathrm{m}^{2}$ compared with two HYVs and one indigenous variety Sadamota. Rice grain yield is positively and linearly related with the number of tillers per unit area [9, 10]. Wang et al [11] suggested selection of genotypes with tillering capacity for obtaining higher yield in rice. The indigenous varieties used in our study were also of high tillering capacity.

Table 3. Variation in morphological characters among five varieties of aman rice.

\begin{tabular}{llll}
\hline Variety & Number of tillers/m & Plant ht. (cm) & Shoot DW (g/hill) \\
\hline BRRIdhan 41 & 205 B & $112 \mathrm{~B}$ & $37.39 \mathrm{~B}$ \\
BRRIdhan 44 & 217 B & $116 \mathrm{~B}$ & $43.72 \mathrm{~B}$ \\
Moulata & 239 A & $134 \mathrm{~A}$ & $47.25 \mathrm{AB}$ \\
Sadamota & 214 B & $140 \mathrm{~A}$ & $56.09 \mathrm{~A}$ \\
Lalmota & 240 A & $141 \mathrm{~A}$ & $52.03 \mathrm{~A}$ \\
CV (\%) & 16.3 & 10.7 & 11.1 \\
\hline
\end{tabular}

The same letter(s) within each column are not significantly different at $\mathrm{P}<0.05$.

Plant height differed significantly across varieties (Table 3). Rice varieties used in the trials could be classified into two distinctly different height groups. Plants of two HYVs were statistically identical but significantly shorter $(114 \mathrm{~cm})$ than the average plant height of three indigenous varieties $(138.3 \mathrm{~cm})$. This was rather expected. The three indigenous varieties were also identical in plant height. Ashfaq et al. [12] also reported the highest genotypic variation in plant height in rice.

Data on shoot dry weight are presented in Table 3. Rice grain yield is related with shoot biomass and partitioning of 
biomass that agronomic management practices can largely influence on [13-14]. Shoot dry weight or biomass is the product of photosynthesis. Rice varieties differed significantly in shoot dry weight which varied from $37.39 \mathrm{~g}$ to $56.09 \mathrm{~g}$ per hill across rice varieties. Generally indigenous varieties had accumulated higher biomass per hill than HYVs. Mean shoot dry weight of indigenous varieties was $51.79 \mathrm{~g}$ per hill as against $40.56 \mathrm{~g}$ per hill recorded for HYVs. Average biomass yield of indigenous varieties was nearly $28 \%$ higher than that of HYVs. Our results are in agreement with those of Jahn et al. [15] who found significant genetic variation in morphological and physiological traits including shoot biomass among the 20 lines and the variation could be largely explained by variety and breeding history (advanced versus landrace).

Two distinctly different groups of rice varieties were grown in the trials and hence wide variation in growth characteristics was not unexpected. However, the major objective was to ascertain how the variation in growth impacts on the yield formation.

\subsection{Grain Yield and Yield Attributes}

Grain yield is the product of the total number of filled spikelets per unit area times the grain size. The number of spikelets per unit area depends largely on the number of panicle bearing tillers per hill or unit area. Rice plant develops tillers on the axil of the plant but all tillers do not bear panicles. Usually more tillers are produced than those survive or produce panicle.

Variation in rice grain yield across varieties and growing seasons is presented in Figure 2. In 2011-2012 growing season depth of tidal flooding particularly in the posttransplanting establishment phase was less compared to that of the succeeding growing season. Repeated cycles of flooding inundated the trial plots following the transplanting of seedlings in 2012-2013 season. The duration of tidal flood immediately following transplanting was also longer in 20122013 growing season. Repeated cycles of inundation due to tidal flooding resulted in hill and tiller mortality (data not shown) causing yield reduction. Rice grain yield is largely related to tillers per unit area $[10,11]$ which in turn is responsible for producing panicles per hill. Tillers are produced in vegetative phase and in the present study repeated inundation of crop owing to tidal flood of varying duration might have presented problem in developing tillers.

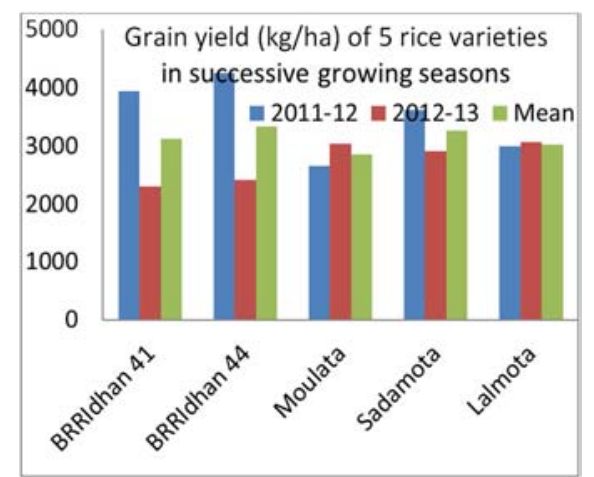

Figure 2. Seasonal difference in grain yield of high yielding and indigenous varieties of rice.

Grain yield ranged from 2,665 $\mathrm{kg}$ to $4,258 \mathrm{~kg}$ per ha across varieties in 2011-2012 season. Yield level generally declined in the succeeding year giving $2,306 \mathrm{~kg}$ to $3,067 \mathrm{~kg}$ per ha. A closer look at the data will reveal that HYVs in the first season gave significantly higher yield than the indigenous varieties but the trend reversed in the subsequent growing season. However, the difference in grain yield between the two groups of varieties was not statistically significant during 2012-13 growing season. Average grain yield decreased in the second season by nearly $28 \%$. Tide related yield reduction was more (42\%) in HYVs than in indigenous varieties $(8 \%)$. In the first year, grain yield varied from 3,941 $\mathrm{kg}$ (BRRIdhan 41) and 4,258 $\mathrm{kg}$ per ha (BRRIdhan 44) between two modern varieties. The corresponding figures for indigenous varieties were between 2,665 $\mathrm{kg}$ and 3,613 kg per ha. On average HYVs recorded about 33\% higher yield compared with indigenous varieties. But the situation reversed in the subsequent growing season recording $21 \%$ higher yield in indigenous varieties compared with modern varieties. Results are in agreement with our previous observations [5] confirming that the indigenous rice varieties perform better in the tidal floodplain.

Average number of panicles per hill recorded for HYVs was 10.75 while indigenous varieties had double the number of panicles (20.83) compared with HYVs. Greater number of hills per unit area in HYVs compensated the effect of larger number of panicles per hill giving identical panicle densities of the two contrasting groups of varieties (Table4) giving an average panicle density ranging between 178 and 205 per $\mathrm{m}^{2}$. Panicle length ranged between $24.1 \mathrm{~cm}$ and $25.1 \mathrm{~cm}$ among the varieties but the difference was not statically significant (Table 4). Panicle length appears to have no bearing on the number of spikelets or on the weight of filled spikelet.

Table 4. Variation in yield contributing characters of HYVs and indigenous varieties of rice (2012-13 growing season).

\begin{tabular}{|c|c|c|c|c|c|c|}
\hline Variety & Panicles per hill & Panicle length (cm) & Panicles per $\mathbf{m}^{2}$ & Spikelets per panicle & Ripening percentage & 1000-grain wt (g) \\
\hline BRRI dhan 41 & 10.5 & 25.1 & 202 & 160 & 76.26 & 24.54 \\
\hline BRRIdhan 44 & 11.0 & 24.5 & 205 & 154 & 67.95 & 28.14 \\
\hline Moulata & 22.9 & 24.9 & 178 & 76 & 88.10 & 28.74 \\
\hline Sadamota & 22.0 & 24.1 & 203 & 81 & 87.5 & 32.24 \\
\hline Lalmota & 19.6 & 24.4 & 194 & 79 & 88.98 & 33.36 \\
\hline $\mathrm{CV}(\%)$ & 12.3 & 9.7 & 18.6 & 14.5 & 5.2 & 6.0 \\
\hline
\end{tabular}

The same letter(s) within each column are not significantly different at $\mathrm{P}<0.05$. 
Indigenous varieties showed greater ripening percentage (number of spikelets/number of filled spikelets x100) than HYVs (Table 4). It was $72.1 \%$ for HYVs as against $88.2 \%$ for indigenous varieties. Grain size or 1000-grain weight varied from $24.54 \mathrm{~g}$ and $33.36 \mathrm{~g}$ across varieties with highest being recorded for Lalmota. Average grain size of indigenous varieties $(31.45 \mathrm{mg})$ was significantly higher than HYVs (26.34 mg).

Differences in grain yield among the varieties or between the two groups of varieties can be explained from the variation in the number of panicles per unit area, number of grains per hill, and grain size. For brevity we consider the yield component data of 2012-2013 growing season only.

\section{Conclusion}

High yielding varieties of rice grown in tidal floodplain ecosystem performed differently in two growing seasons. Extent of tidal flooding during the post-transplanting phase was critical in the performance of HYVs. Survival of seedlings following transplanting depends largely on the depth of tidal flood. In 2011-2012 growing season depth and duration of tidal flood was within the range of tolerance of HYVs and outyielded the indigenous varieties. Seedlings subjected to repeated cycles of inundation in the second year of study suffered resulting in poor yield. In contrast, indigenous varieties better survived tidal flood and performed relatively better. Therefore direct comparison of yield performance of HYVs and indigenous varieties in tidal floodplain presents problem. Since the extent of the depth and duration of tidal flooding cannot be predicted beforehand, growing HYVs of rice and achieving higher yield remains a matter of chance. It is conceivable that until high yielding varieties capable of producing longer seedlings are evolved, farmers in the tidal floodplain will have no other choice but growing indigenous rice varieties in aman season.

\section{Acknowledgements}

Mohammad Altaf Hossain supervised the on-farm trials but did not survive while writing the manuscript. Krishi Gobeshona Foundation provided financial assistance for conducting the study. We also thank the participating farmers who helped us performing the trials.

\section{References}

[1] SOIL RESOURCE DEVELOPMENT INSTITUTE (SRDI). Saline Soils of Bangladesh. Government of Bangladesh, Dhaka. 2010.

[2] SHAMSUZZAMAN, K.M., HAQUE, M.M. Performance of modern varieties of transplanted aman rice and mungbean in selected locations in tidal floodplain, pp. 26-30. In Crop
Production in the Coastal Ecosystem: Challenges and Opportunities, Agrarian Research Foundation, Dhaka, 2010.

[3] ROY, B. C., HOSSAIN, M. A. AND KHAN, M. A. I. Suitable transplanting time for the modern $t$. aman rice varieties in tidal non-saline wetland situation of Bangladesh. Pakistan J. of Biol. Sci., 6, 661665.2003.http://dx.doi.org/10.3923/pjbs.2003.661.665.

[4] DAS, G. C., SAMANTA, S. C., BISWAS, P., SAHA, N. K. BHATTACHARYA, J. Effects of sowing methods on yield attributes and yield of aus rice under the tidal ecosystem. J. Biosci. Agric. Res. 4(1): 01-09. 2015.

[5] HAMID, A., ULLAH, M. J., MOLLAH, M. F. H., AKBAR, M. A. Traditional rice varieties perform better in tidal floodplain. Intl. J. Adv. Res. 3: 1316-1321. 2015.

[6] SARKER, R. K., DE, R. N., REDDY, J. N., RAMAKRISHNAYA, G. Studies on the submergence tolerance mechanism in relation to carbohydrate, chlorophyll and specific leaf weight in rice (Oryza sativa L.). J. Plant Physiol. 149:623-625, 1996.

[7] HAQUE, K. M. S., KARIM, M. A., BARI, M. N., ISLAM, M. $\mathrm{R}$. Genotypic variation in the effect of drought stress on phenology, morphology and yield of aus rice. Intl. J. Biosci.8 (6): 73-82, 2016.

[8] AHMED, A. R., DUTTA, B. K., D. C RAY. Response of some rice varieties to different crop management practices towards morphological and yield parameters. Intl. J. Sci. Res. Pub. 5(2): 1-6. 2015.

[9] SAN-OH, Y., KONDO, M., OOKAWA, T., HIRASAWA, T. Ecophysiological analysis on effect of planting pattern on biomass production and grain yield in rice. JARQ 42 (2), 7989.2008 .

[10] Huang, M., Zou, Y., Lian, P., Xia, B., Ibrahim, M., Ao, H. Relationship between grain ield and yield components in super hybrid rice. Agr. Sc. China 10:1537-1544. 2011.

[11] WANG, F., CHENG, F., ZHANG, G.Difference in grain yield and quality among tillers in rice genotypes differing in tillering capacity. Rice Sci. 14(2): 135-140. 2007.

[12] ASHFAQ, M., KHAN, A. S., KHAN, S.H.U., S.H.U. AHMAD, R. Association of various morphological traits with yield and genetic divergence in rice (Oryza sativa L.). Int. J. Agric. Biol., 14: 55-62. 2012.

[13] TANG, L., ZHU, Y., HANNAWAY, D., MENG, Y., LIU, L., CHEN, L., CAO, W. RiceGrow: A rice growth and productivity model. NJAS - Wageningen J. Life Sci.57(1): 8392. 2009.

[14] SHEEHY, J. E, MITCHELL, P. L. 2013. Designing rice for the 21st century: the three laws of maximum yield. Discussion Paper Series 48. Los Baños (Philippines): International Rice Research Institute. 19 p.

[15] JAHN, C. E., MCKAY, J. K., MCNALLY, K. L., MAULEON, R., STEPHENS, J., BUSH, D. R., LEUNG, H., LEACH, J. E. Genetic variation in biomass traits among 20 diverse rice varieties. Plant Physiol. 155: 157-168. 2011. 